\title{
A Identidade Nacional Brasileira
}

\author{
MICHEL DEBRUN
}

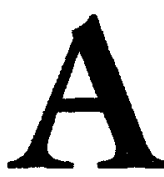

presentamos a seguir os principais temas e articulaçōes de um trabalho em andamento sobre a identidade nacional brasileira:

1. O que é ser brasileiro? Será mesmo que faz sentido falar desse ser?É fácil afirmar a existência da Nação brasileira, se atentarmos apenas para os aspectos geográficos, jurídicos ou diplomáticos. E definir a identidade brasileira como o atributo, a etiqueta do conjunto populacional, ou dos indivíduos, que vivem dentro desse quadro formal. Mas parece que Nação e identidade nacional exigem algo mais. Como, por exemplo, um consenso em torno de certos valores, e uma diferença entre ele e outros tipos de consenso, ou entre eles e outros consensos nacionais. Ora, desde os fins do século XIX, muitos têm duvidado seja da coesão brasileira seja da diferença específica do Brasil.

2. Hoje essas dúvidas se acham reforçadas, face a três categorias de indagaçóes:

a) Como poderia haver consenso de base num país caracterizado historicamente por consideráveis desigualdades econômicas, sociais, culturais e políticas - entre classes, etnias e regióes - e, no momento, pelo agravamento das dificuldades

socioeconômicas? Principalmente se observarmos o aumento da marginalidade, da criminalidade, do enclausuramento dos ricos $\mathrm{e}$ poderosos - fenômenos que parecem assinalar, aos olhos de alguns, a ressurreição, perversa, de uma sociedade de estamentos.

b) Como poderia o nível nacional manter uma significação central, se o que presenciamos é a proliferação das identidades locais, de bairro em particular? A novidade nấo é apenas quantitativa como qualitativa: a diferença com o passado é que, agora, tais identidades não parecem mais se situar em relação a uma identidade nacional; ou seja, não reconhecem a capacidade de regulação e arbitragem em última instância do Estado Nacional. Esse Estado é percebido como instância de coação pura.

c) Não é também o nível nacional minado por cima, devido ao crescente cosmopolitismo da cultura? Mesmo porque esse 
cosmopolitismo não é igualitário, e repercute no seu âmbito as dissimetrias e desigualdades que acompanham a internacionalização da economia.

3. Tais indagaçóes têm suscitado dois tipos de respostas:

a) Há quem exclui pura e simplesmente a existência de uma identidade nacional brasileira. Se tanto é que existiu no passado, ela estaria sumindo. Náo se pode negar, admitem, a presença de certos traços etnoculturais comuns à maioria da população brasileira; embora esses traços sejam diversamente modulados conforme as regiōes, as classes sociais, os níveis de instruçăo. Esses traços, manifestos por exemplo nas religiōes populares, nas atividades lúdicas, nas distinçốes operadas entre a Casa e a $R u a$, podem definir uma brasilidade. Até um caráter nacional, em que pesem as conotaçóes ideológicas e simplificaçóes que, via de regra, acompanham essa noçáo. Mas não há consenso nacional em torno de valores básicos. Nem para defender ou promover aqueles valores revelados pelos traços etnoculturais. $O$ que presenciamos é, táo-somente, a generalizaçáo e a repetição de certos fenômenos socioculturais em toda a extensáo do território dito nacional. Nada indicando que o atomismo tantas vezes atribuído (Alberto Torres, Oliveira Vianna, Nestor Duarte) à sociedade brasileira tenha sido superado. $E$, na falta de um consenso com que ela poderia se articular e se combinar, a própria brasilidade - ou seja, a diferença entre o Brasil e as outras naçóes - está fadada a resvalar para o folclore, para o atrativo turístico. A sucumbir, também, ao rolo compressor dos cosmopolitismos.

b) Outros, porém, pensam que a denúncia da inexistência da identidade nacional brasileira é insuficiente. Pois não há como negar que o discurso da Nafão - quer se apresente como discurso sobre a Naçáo, para a Nação ou da própria Nação está florescente, em particular na imprensa. Lemos constantemente frases do seguinte gếnero: "A Nação assiste estarrecida e indignada a tal acontecimento". Isso revela uma substancializaçáo, uma ontologização da Naçáo. E, no rastro dela, os brasileiros, ou muitos deles, se imaginam portadores de uma identidade nacional. Devemos, portanto, explicar essa aparente contradiçáo: como entender que a referência à Naçáo brasileira e à identidade nacional brasileira seja moeda corrente, se essa referência náo corresponde a nada de real?

É a indagaçōes desse tipo que procuravam responder os "Ensaios sobre o Nacional e o Popular na Cultura Brasileira" 1 , no início da atual década. Tentemos articular e sistematizar as teses difusas nestes "Ensaios":

- Certos grupos ou instituiçóes têm a preocupação de difundir a temática da Naçáa - isto é, expressōes como identidade nacional, auto-afirmafão nacional, cultura brasileira, etc. É que essas expressóes sugerem, senão a negação da própria existência da luta de classes, pelo menos a obrigaçáo de

(1) Ensaios coordenados por Marilena Chauí. 
subordinar os interesses e identidades de classe - ou de regióes, etnias, famílias, indivíduos - a um interesse geral e a uma entidade mais abrangente.

- A articulação e a difusão do discurso nacional não obedece, portanto, à intençáo acadêmica de explicitar o significado dos termos e expressốes desse discurso. Ou melhor, mesmo quando essa intençấo está presente, ela não constitui um passo autônomo. Acha-se integrada, entre outros elementos, a uma estratégia de poder. De forma que o que esse discurso propóe não é um estudo, mas uma ideologia da Nação, da identidade naciónal, do interesse nacional, da cultura nacional, etc.

- Essa conotação ideológica não seria, por si só, depreciativa. Só que o discurso nacionalnáo vai, como querem imaginar, ao encontro de um anseio genuíno das camadas populares. Se fosse o caso, as elites - portadoras do nacional - se limitariam apenas a formular e sistematizar - como os intelectuais, segundo Gramsci - sentimentos e aspiraçóes comuns a todos; teríamos, entáo, o nacional-popular. Ou seja, o consenso de muitos em torno de certos valores; e a identidade nacional definida, em nível coletivo, como sendo o próprio consenso, e, em nível individual, como a participação de cada um nesse consenso. Mas tal não é o caso: o que é nacional, no Brasil, não é popular; e o que é popular não é nacional. O elemento popular se exprime através de várias identidades, religiosas, lúdicas, etc., sim, baseadas no consenso dos seus participantes. O conceito de nacional-popular é vazio, pelo menos na atualidade brasileira.

- Nessas condiçóes o discurso nacional tende a se esgotar em si mesmo e nas vontades ou práticas de poder que lhe são associadas. Vontades, aliás, conflitantes entre si e que disputam a apropriaçáo do símbolo Nação. Se é assim, a Nação não é senáo a encruzilhada ou o conjunto, movediço, dos discursos concernentes à Nação, à identidade nacional, ao nacional-popular, etc., aos quais convém acrescentar outras linguagens, como os ritos comemorativos da nacionalidade. Logo a ideologia da Naçáo e a Naçáo se confundem, mesmo que a primeira possa conter, num ou noutro ponto, alguma verdade objetiva.

- No entanto, o discurso nacionalou tal das suas variantes, de direita ou de esquerda, pode alcançar certa ressonância popular, devido ao fato de que ele não é simples palavra ou ideologia solta no ar, mas se insere numa rede complexa de práticas de dominaçáo. Desta forma podemos dar outra definiçáo da Naçáo: é a comunidade em que certo tipo de discurso sobre a Naçáo tem razoável aceitaçấo. Mas fica entendido que essa aceitação não tem nada de nacional-popular (tal como o nacionalismo imagina o nacional-popular); é algo artificial, postiço, logo precário, apesar da pressão dos aparelhos ideológicos de Estado e outros. A difusão generalizada da temática da Naçáo não contradiz, portanto, a crise que a idéia de Naçáo parece estar atravessando, hoje, no Brasil. 
As teses dos "Ensaios..." (ver nota 1) estão discutidas ao longo do nosso trabalho.

4. Endossamos em grande parte a análise crítica do nacional-popular, tal como ele se apresenta em certos aspectos da atualidade brasileira, isto $e$, como unidade ilusória e, portanto, como ideologia dele próprio. Crítica parecida já estava presente no trabalho inovador de Carlos Guilherme Mota sobre "A Ideologia da Cultura Brasileira". Nos dois casos trata-se de desmistificar, ou desarticular, entidades (a cultura brasileira ou o nacional-popular) que se oferecem como evidentes, como não-suscetíveis de serem questionadas. Fazemos, todavia, três tipos de ressalvas às análises críticas dos "Ensaios..." :

a) O conceito de nacional-popular náo parece intrinsecamente vazio, ou contraditório. Como o queriam outrora Renan, à direita, e Gramsci, à esquerda, pode haver em tese - e provavelmente houve na história das velbas naçóes - uniāo real, embora parcial, do nacional e do popular. Ou seja, pode haver consenso popular em torno de valores nacionais e identidade nacional de quem participa desse consenso.

As diferenças ou oposiçóes de classe ou etnias, regióes, etc. invocadas para demonstrar a impossibilidade de tal consenso náo devem nos fazer esquecer que a invenf̧ăo da Naçáo, das primeiras naçōes, se deve precisamente à necessidade de criar um liame forte - portanto nāoartificial, nāoredutível a uma ideologia do liame ou a um discurso sobre o liame - entre elementos muito heterogêneos. Naçóes homogêneas, como a atual Polônia composta quase unicamente de elementos ao mesmo tempo poloneses e católicos -, são a exceção, não a regra. Mais exatamente a Naçáo originou-se do descompasso entre duas categorias de fenômenos, a partir do século XVI:

- Grande complexidade das sociedades ocidentais em termos de regióes, etnias, estamentos e classes (incipientes).

- Paralelamente a unidade infra-estrutural crescente dessas sociedades, pela generalização da economia capitalista e pela articulaçáo de todos com todos através da divisáo do trabalho (a solidariedade orgdnica de Durkheim). Cria-se um espaço econômico unificado, progressivamente despojado de barreiras e limitaçōes corporativas.

A invençáo da Nação - ou melhor, a transformação em Naçáo de um espaço político previamente circunscrito e fechado pelos acasos de uma história dinástica, militar, etc. - se dá sob o impulso inicial do Estado, para igualar os dois aspectos acima expostos. O primeiro deve se equiparar ao segundo, a sociedade deve se tornar para sio que ela já é em si, em núvel econômico infra-estutural. Ou seja, unificada. Esse para si, por sua vez, só pode ser algo espiritual,seja qual for a maneira de interpretar essa espiritualidade. Não necessariamente como uma fussío das conscitncias, operada pela solidariedade mecdnica, como queria Durkheim. O essencial é destacar os dois aspectos. Primeiro, a Naçáo tem um caráter abstrato: mesmo nos momentos de entusiasmo coletivo, ela náo é sentida por seus membros como é sentida, por exemplo, uma comunidade local ou uma 
propriedade como a brasilidade. Mesmo baseada no consenso, ela paira em cima do social imediato. Segundo, e correlativamente, ela comporta uma esfera priblica - no sentido de Habermas e, antes dele, do Marx da "Questão Judaica" -, na qual ou em torno da qual são tratados, hierarquizados ou reestruturados os interesses das várias categorias de participantes, a fim de se chegar à definição de um interesse geral. Definição movediça, sujeita à flutuação das relaçōes de dominação, mas que, salvo em épocas de decadência ou de crise, busca a transformação dessas relaçóes em relaçăo de hegemonia, em virtude da própria necessidade que deu ensejo ao invento da Naçáo. A identidade nacional, da sociedade como um todo no sentido em que Braudel fala da "identidade da França" se torna entáo possível, e não como mero artefato ideológico. Em que pesem os conflitos, mesmo quando irredutíveis, de classes, etnias ou regiōes.

b) Deve-se reconhecer que, no âmbito cívico-político, o Brasil de hoje destoa bastante desse tipo ideal do nacional-popular. $\mathrm{O}$ próprio êxito, relativo embora, do discurso nacionale das identidades nacionais outorgadas que ele fabrica, revela que ele se impóe - ou se impôs até o momento - num semivácuo. $\mathrm{Ou}$, mais exatamente, devido à impossibilidade secular em que se encontrava a grande massa da população de romper certos bloqueios históricos e de ter acesso numa ação coletiva autônoma, geradora de uma nova identidade nacional. Mas a idéia, subjacente nos "Ensaios...", de que as massas são, no fundo, alheias à questão nacional - só lhes interessariam as identidades de classe, ou de base - , e por isso mesmo superficialmente manipuláveis, esbarra em duas objeçóes. De um lado, pode haver um potencial popular pronto a cristalizar nesse sentido (e esse tema está desenvolvido na conclusão do trabalho). Mesmo porque a proliferação, já referida, das identidades de base necessita um quadro global em relaçáo ao qual, e dentro do qual, ela possa se situar; e porque esse quadro não pode ser, desde já, nem uma comunidade universal nem mesmo uma comunidade latino-americana. De outro lado, mesmo em se tratando do nacional-popular ilusório apontado pelos "Ensaios...", encontramos o seguinte dilema:

- Ou constata-se que o discurso nacional náo pega junto a seus destinatários e então sua inutilidade já deveria ter ficado evidente. E o discurso, sumido do palco;

- Ou entáo se constata que ele pega, quando nada em superfície. Mas, neste caso, parece difícil explicar essa aceitação só pelo peso das práticas de dominação. $O$ discurso nacional deve encontrar ancora, senáo numa identidade nacional já presente no ouvinte, pelo menos num anseio para que tal identidade se desenvolva, eventualmente dirigida contra as práticas de dominaçáa associadas a esse discurso. De modo geral, a possibilidade de reduzir a Naçáo e a identidade nacional à ideologia da Nação ou da identidade nacional - de fazer tudo caber deniro da ideologia "De"e do discurso "Sobre" - 
constitui uma possibilidade-limite. Onde quer que haja uma certa continuidade e generalidade do discurso nacional, as coisas nunca podem alcançar esse limite, se bem que possam se aproximar dele.

c) As próprias análises dos "Ensaios..." deixam vislumbrar a possibilidade de um nacional-popular autêntico. As críticas que dirigem ao nacional-popular dizem respeito, sobretudo, ao caráter ilusório de um consenso nacional político, ou cívico-político, em torno de objetivos também políticos, como a realização de objetivos do tipo Pátria Grande ou Brasil-Poténcia. O nacional-popular, na esfera cultural, não parece criticado enquanto tal; ou seja, não se exclui que haja um consenso - no caso, uma comunhão - em torno, por exemplo, da música popular - ou popular/erudita - brasileira. Quando José Miguel Wisnik avalia o propósito, por parte de Villa-Lobos durante o Estado Novo, de espalhar os coros orfeônicos pelo Brasil afora, ele não acha ilegítima a possibilidade de que, com isso, o Brasil se transforme numa festa, num imenso auto-espetáculo. Denuncia, apenas, a intenção de fazer do coro um instrumento de integração sociopolítica: pois cada coro devia se tornar um microcosmo de Brasil novo, e exemplificar a unidade do país e o disciplinamento das paixōes pretendia-se, a partir de um nacional-popular musical eventualmente autêntico, suscitar ou reforçar uma comunidade política ilusória.

5. A idéia de um nacional-popular cultural - e de uma identidade nacional nele baseada - é, aliás, um tema familiar para toda uma tradição antropológica e/ou literária. Procuram circunscrever uma brasilidade. Mas, a partir dela, vão além. $O$ que lhes interessa, sobremaneira, é que a cultura, através dos seus portadores, se torne auto-referencial - sem se fechar numa torre de marfim, ao contrário - e vise seu próprio alargamento e aprofundamento. Nisso consiste sua universalidade. Nāo há, é claro, imperativos categóricos, que seriam do tipo devemos todos desfrutar o Carnaval; nem mesmo se pode decretar "devemos praticar um anticarnaval", um carnaval da miséria, como aquele encenado pọr Joãozinho Trinta. Tais imperativos representariam uma invasão da esfera sociocultural por atitudes éticas ou ético-cívico-políticas. Mas parece que a idéia de esfera pública com valores a serem protegidos ou promovidos, pelo desejo senăo por obrigação - está presente no campo cultural também.

É esse aspecto que aparece na interpretação que Maria Isaura Pereira de Queiroz dá do Carnaval. Este é visto, em certas das suas manifestaçōes, como uma forma de auto-afirmaçăo popular, que concerne potencialmente a muito mais gente do que o pequeno grupo diretamente envolvido. E também é algo essencialmente cultural. Pode ser, é verdade, que haja nisso uma forma de protesto contra a impossibilidade de uma participaçáo política efetiva, em particular em nível nacional. Mas, mesmo nesse caso, isso não significa que $o$ Carnaval seja praticado como uma atividade política de segunda categoria, ou disfarçada, ou indireta. Simplesmente, face às dificuldades presentes para participar de uma vida política autêntica, se optou por outra forma de vida, em que se torna possível uma experiência comunitária, que desejam por sua vez estender em nível 
nacional. Em Roberto da Matta encontra-se uma idéia parecida: com o Carnaval presenciamos o advento de uma comunidade efêmera, mas real e original, que permite agüentar ou compensar até certo ponto as agruras da sociedade, caracterizada, esta última, por separaçóes, antagonismos e hierarquias.

Outras experiências - $\mathrm{e}$ também reflexōes sobre essas experiências, $\mathrm{e}$ reiteraçôes das experiências a partir das reflexóes - visam aprofundar outra vertente da identidade nacional cultural. Menos seu aspecto comunitário, de comunhão, do que sua diferença, sua especificidade. Náo forçosamente como quer o nacionalismo ingênuo, pela recuperação e expansão de uma cultura originária que teria, até o momento, ficado soterrada ou marginalizada. Nem pela constituição, em seu favor, de uma reserva de mercado. Mas pela multiplicação das interaçóes entre a cultura cosmopolita (ou portuguesa, francesa, anglo-saxônica) que vem se reiterando desde os primórdios do Brasil (e que talvez mereça melhor a denominaçáo de originária), e uma cultura endógena que, em seguida, se firmou aos poucos. Pode-se conceber, entre o pólo exógeno/endógeno o o pólo endógeno inúmeras modalidades de empréstimos, alianças, antagonismos. Pode continuar também havendo interpretaçōes recíprocas, de cada pólo pelo outro um sendo visto como residual e folclórico, o outro como artificial, fora de lugar. O essencial, porém, aos olhos dos que defendem a idéia de uma dualidade básica da cultura brasileira, é que ficam excluídas, seja a fusảo harmoniosa dos dois pólos, seja a expulsão de um deles pelo outro, seja a sua coexistência pacífica mas estanque. A propósito deste último ponto: não há, como em outros lugares, duas culturas, uma para o povo, outra para as elites, embora possam se desenvolver acentuaçóes num ou noutro sentido; cada brasileiro seria portador, ao menos em potencial, da mesma dualidade - que, aliás, foi explorada, em nível auto-referencial, por obras como as de Mário e Oswald de Andrade, e pelo Tropicalismo. É nessa igualdade tensa que residiria e sem perspectiva de superaçáo a curto e médio prazos - a identidade nacional cultural brasileira.

Há também a possibilidade de uma interação generalizada entre regióes, etnias, classes. $\mathrm{E}$ isso interessa tanto ao aspecto comunitário como ao aspecto da diferença da identidade cultural. Náo há mais, apenas, generalizaçáo do Carnaval, do samba, do futebol - por justaposição, por exemplo, de inúmeros microcarnavais através da imensidão brasileira - mas a transformaçáo, mediada pela TV, do Brasil em imenso auto-espetáculo. A nova transparência do espaço

A identidade nacional brasileira nāo é uma só. As suas dimensöes política e cultural, em particular, não têm caminhado juntas.

Nem remetem a um mesmo espírito...

permite a todos presenciarem todos, pularem com todos. Parece que o privatismo da sociedade brasileira não é, nessa área, incompatível com a expansão do universal, da esfera pública. Cada um pode, ficando no seu lugar, participar de tudo com todos. Náo há a dialética tensa de público e de privado, que vigora, ou deveria vigorar, na área política. Mas uma transiçáo e uma oscilação suaves entre os dois pólos.

Ocorre algo parecido com a novela. Esta, hoje, vale menos pelo seu conteúdo, que pode ir de conservador a vagamente progressista, do que pelo fato de pôr todos em contato com todos: para onde quer que eu vá, sempre encontrarei pessoas para narrar ou comentar o capítulo da véspera. É aqui, talvez, que Mac Luhan tem razáo: o meio é a mensagem. Mas há uma contrapartida: o conteúdo de uma novela, 
mesmo quando corrosivo, não mobiliza ninguém - pelo menos quando a participação na televisão se limita a si própria (o que, hoje, é a regra), náo se inserindo num quadro mais amplo de práticas sociopolíticas.

6. A partir desses vários pontos é possível esboçar três teses, que estamos desenvolvendo no momento:

a) A identidade nacional brasileira não é uma só. As suas dimensōes política e cultural, em particular, nảo têm caminhado juntas. Nem remetem a um mesmo espírito, à diferença do que acreditava Gilberto Freyre, para quem a tolerância mútua que reina na área sociocultural das relaçóes humanas devia se traduzir, com naturalidade, por igual tolerância na área política: o liberalismo nosso náo devia nem podia fundamentar-se, como o liberalismo anglo-saxônico, na competição onde ganha o melhor ou o mais astuto, mas na conciliação harmoniosa das diferenças. Não é bem assim: existe de fato, no Brasil, uma forma política da conciliação, mas esta, longe de se definir pela tolerância mútua, descansa na cooptação mais ou menos forçada do menos forte pelo mais forte.

b) $\mathrm{O}$ advento de uma identidade nacional forte, na área cívico-política, tem sido bloqueado desde as origens. Pretende-se mostrar como se estabeleceram mecanismos de reprodução quase automática das grandes desigualdades - o que dificultou, e ainda dificulta, a emergência e, sobretudo, a continuidade do nacional-popular. $\mathrm{Na}$ falta daquela identidade floresceram pseudo-identidades: umas artificiais outorgadas pelos grupos dominantes, pela Igreja, pelo Exército, pelo Estado; outras mais naturais, mas raquíticas, por resultarem, seja da acomodação dos atores às estruturas de dominação (caso da identidade fisiolbgica), seja da sua revolta, mas desprovida de bases, contra essas estruturas (caso da identidade ideologica). Os atores oscilavam - oscilam - entre essas várias identidades. $O$ que significa que o ator não ancorapa em nenhuma delas (nâo se identifica com a própria identidade) e que, como conseqüência, sua atuaçáo era lábil, inconstante, pronta aos abandonos e recomeços. $\mathrm{O}$ abalo, ou mesmo a ruptura, hoje, de certos bloqueios permite todavia encarar a possibilidade de uma nova identidade, ao mesmo tempo menos oscilante e mais capaz de servir de pivô, de raiz para uma ação sociopolítica coerente e de longa duração.

c) No âmbito sociocultural não houve bloqueios parecidos, apesar do fato de um elemento impulsionador essencial, o negro, ter sido marginalizado - nesse âmbito também - até a década de 20, quando as perseguiçóes ao samba de morro e aos terreiros de Candomblé começaram a diminuir. Essa expansáo da esfera sociocultural, e de identidade nacional que se gera durante 0 processo, parece ter várias explicaçōes. Citemos apenas duas. Primeiro, a própria pujança da afirmaçáo negra e de outras camadas, marginalizadas ou subalternas. Essa pujança é, ao mesmo tempo, um fenômeno naturale uma resposta dessas camadas à sua exclusão da identidade cívico-política efetiva 
(senáo teórica). Segundo, a tentativa por parte dos grupos dominantes de neutralizar as aspiraçōes cívico-políticas das camadas subalternas, valorizando, depois de tê-la combatido (até os anos 20), uma comunidade cultural nacional de que eles próprios podem fazer parte. $O$ que representa, de um lado, uma estratégia pálbula de escape (dirigida aos grupos subalternos) $\mathrm{e}$, de outro lado, uma integraçáo real, e não apenas ideológica, de todos os brasileiros, ricos e pobres. Só que essa integraçáo, apesar de enaltecida, é simultaneamente folclorizada e no limite turistificada pelos de cima, por ser apenas culturale polarizada em torno de valores de origem afro-brasileira.

7. Para tentar entender a gênese da dualidade entre identidade política e identidade cultural, e avaliar as possibilidades da sua evoluçáo, temos utilizado, como fio condutor, a "Ideologia da Realidade Brasileira" . Entende-se por isso o conjunto das posiçóes que, a partir de uma concepção global da sociedade brasileira e da sua história, procuram tirar ilaçóes no que diz respeito à especificidade e ao destino dessa sociedade, da sua política da sua cultura. O termo ideologia não é utilizado num sentido pejorativo. Mesmo porque constam, no elenco dos trabalhos a serem analisados, obras de consagrada reputação científica. A intenção é tão-somente indicar que esses trabalhos se situam numa perspectiva engajada, seja ela explícita ou não.

A escolha desse conjunto ideológico, como fonte principal de reflexáo sobre a identidade nacional brasileira, se prende ao fato de que, na maioria dos autores em foco, manifesta-se uma preocupaçáo dominante pela constituição ou pela preservação da Naçăo brasileira; e pelos obstáculos, bloqueios, meios, caminhos que podem dificultar ou facilitar a consecuçáo desses objetivos. Tudo isso dentro de uma perspectiva histórica, que pretende apontar fenômenos de longa duraçáo, para além da diversidade das conjunturas. Espera-se do estudo da "Ideologia da Realidade Brasileira" três fontes de informação:

a) Os autores, mesmo os mais ideológicos (desta vez no sentido mais usual: pensamos em escritores como Oliveira Vianna, Gilberto Freyre, Cassiano Ricardo, Álvaro Vieira Pinto, Oliveiros S. Ferreira, etc.), podem apresentar, sob tal ou qual ponto, uma visão aceitável da identidade nacional brasileira. Ou seja: podem dar uma idéia da existência ou da inexistência dessa identidade; se existir, do seu caráter incipiente ou plenamente confirmado; do seu caráter global ou apenas setorial (restrito, por exemplo, ao âmbito cultural); ou das diferenças entre ela e outras formas de identidades nacionais; ou das causas disso tudo.

b) Por outro lado, grande parte desses autores formam, juntos, um campo estrutural. Em dois sentidos. Primeiro, defendem posiçóes arquetípicas, isto é, recorrentes desde pelo menos o início do século, e as atitudes políticas e culturais concretas a que estão ligadas essas posiçóes também são recorrentes e se revezam no papel hegemônico. Exemplos de tais atitudes, no âmbito político: a conciliafão, o autoritarismo desmobilizador, $\mathrm{o}$ autoritarismo mobilizador. Segundo, pelas próprias modalidades da sua recunrência, da sua oposição e do seu revezamento, essas 
posiçóes revelam indiretamente características do contexto social, político e cultural. É essa ida do texto ao contexto que queremos praticar e explorar. Náo forçosamente no sentido de detectar interesses subjacentes de classes ou de etnias. Mas, sobretudo, de mostrar que certas coisas não poderiam ser ditas, ou seriam ditas de outro modo, se o contexto não apresentasse certos vazios, certas lacunas.

Tomemos um exemplo. No que diz respeito à identidade política - ou ao aspecto político da identidade brasileira encontramos entre os autores uma dicotomia bastante rígida. Ou essa identidade é vista como $j a ́$ dada, no que tange ao essencial, seja a partir de um acontecimento fundador que se cristalizou em tradiçăo, seja a partir de uma lenta sedimentaçáo de traços etnoculturais. Ou então, a identidade é vista como a fazer - ou a refazer na perspectiva de alguns isebianos - a partir de um projeto radical de liberdade individual ou coletiva. Em termos śartrianos poderíamos dizer que lidamos com a oposiçáo brutal do em sie do para si. Ora as identidades normais nacionais e outras - escapam dessa dicotomia. Constituem-se, é claro, a partir de dados da geografia, da economia, das etnias, etc., no caso das identidades nacionais. $\mathrm{Na}$ outra ponta, se traduzem em projetos, e, no caso da Naçăo, há sempre uma luta entre vários projetos, que pretendem interpretá-la e capturar o símbolo Nação. Mas exíste também um andar intermediário: 0 das interaçōes coletivas de base, as quais, quando são efetivas isto é, quando não são constituídas por meras relaçóes de força -, dão ensejo ao surgimento e ao desenvolvimento de uma esfera pública. Essas interaçōes, e seus resultados por sua vez, se desenvolvem através do tempo, permitindo a constituição de uma memória coletiva que constitui o núcleo da identidade nacional: é nela que os dadossão transformados em projetos; é a partir dela, também, que os projetos, embora livres e não se reduzindo a um simples prolongamento do passado, vão aparecer como mais ou menos enraizados ou mais ou menos gratuitos, e, por isso, capazes ou não de adquirir força histórica. Ora, a ausência quase geral de referências, na literatura política brasileira, a esse núcleo deixa supor que ele é de fato inexistente. E que, talvez, náo se possa até o momento falar, no sentido forte, de uma identidade política brasileira, embora haja possíveis suceddneos.

c) Outro recurso oferecido pela "Ideologia da Realidade Brasileira" reside no seu engajamento. As suas propostas - no sentido de redescobrir, ou de forjar, ou de completar a identidade nacional - hăo de ser vistas, elas próprias, como manifestaçóes da identidade nacional, ou da sua ausência, ou do seu caráter incipiente, ou do seu fracasso. Por exemplo, o ISEB definia a Nação como o projeto de fazer existir a Nação (a Nação é auto-referencial, ela deve querer a si própria) através do desenvolvimento; e definia a identidade nacional, ou simetricamente a antibrasilidade, pelo fato de se associar ou não a esse projeto. Ora, essa atitude, assim como atitudes semelhantes dos Centros de Cultura Popular (CCP), se 
consubstanciou, no fim dos anos 50 e início dos 60 , numa prática mobilizacionista que pode ser encarada não só como uma tentativa de fazer surgir a identidade nacional a partir da ideologia e da educaçăo ideológica, mas também como um esboço de tal identidade. Esboço fracassado, como se viu $\mathrm{em}$ seguida, já que não emergia de uma memória histórica na qual ele pudesse se alicerçar. Se autoconcebia como sem passado e era de fato sem passado. Reduzindo-se, por isso mesmo, a uma simples tentativa de autoritarismo mobilizador.

8. O trabalho comporta também um capítulo teórico, em que se pretende definir:

a) O que é identidade, de modo geral. Procura-se mostrar que toda identidade humana implica năo apenas uma certa permanência através do tempo (o que Paul Ricoeur chama de mesmice), mas também um aspecto auto-referencial; a identidade deve se enunciar, se reiterar, para ser ("Eu sou eu mesmo"). Essa reiteraçăo, nós a chamamos - também utilizando Ricoeur - de ipseidade. Finalmente temos um terceiro patamar, no qual a identidade interpreta a si própria, se discute, quer se modificar, se projeta de tal ou qual maneira rumo ao futuro. Esse patamar é o da auto-reflexividade, que constitui um redobramento da auto-referencialidade.

b) O que é uma identidade de grupo. Ou seja, quais as complexidades novas trazidas pela interação entre vários pólos no seio de uma mesma identidade? Até que ponto é legítimo usar uma expressão como consciencia coletiva?

c) O que é, especificamente, a identidade nacional. As páginas acima dão alguma idéia da nossa posiçáo a respeito.

Michel Debrun, professor de Ciência Políica da UNICAMP e membro da área de concentraçāo de História das Ideologias e Mentalidades do IEA. 